\title{
USING ARTIFICIAL NEURAL NETWORKS IN ESTIMATING WOOD RESISTANCE
}

\author{
Eder Pereira Miguel, ${ }^{1, \$}$, Rafael Rodolfo de Melo², Laércio Serenini Junior ${ }^{3}$, \\ Cláudio Henrique Soares Del Menezzi ${ }^{1}$
}

\begin{abstract}
The purpose of this research was to evaluate the potential of Artificial Neural Networks in estimating the properties of wood resistance. In order to do so, a hybrid of eucalyptus (Eucalyptus urograndis) planted in the Northern Region of the State of Mato Grosso was selected and ten trees were collected. Then, four samples of each tree were removed, totaling 40 samples, which were later subjected to non-destructive testing of apparent density, ultrasonic wave propagation velocity, dynamic modulus of elasticity obtained by ultrasound, and Janka hardness. These properties were used as estimators of resistance and compressive strength parallel to fibers, and hardness. Multilayer Perceptron networks were also employed, training 100 of them for each of the evaluated parameters. The obtained results indicated that the use of Artificial Neural Networks is an efficient tool for predicting wood resistance.
\end{abstract}

Keywords: Artificial intelligence, Eucalyptus urograndis, hardness, mechanical properties, nondestructive testing.

\section{INTRODUCTION}

The genus Eucalyptus is among the most successful commercially-planted tree species in the tropics, mainly due to its rapid growth, species diversity and a wide range of industrial uses. Brazil is one of the countries where clonal forestry of the Eucalyptus genus has developed the most.

The Eucalyptus urograndis is a hybrid developed in Brazil by crossing the species E. grandis $\mathrm{x} E$. urophylla. The first plantation of E. urograndis took place in the state of Espírito Santo in 1979, but it was in the 1990s that this species boosted the rate of forest growth, as well as a more homogeneous quality of planted forests.

This hybrid is currently one of the most planted forest essences in the country, constituting the basis of Brazilian clonal forestry. One of the most planted clones in the world is H13, which is widely used by several companies to produce wood for cellulose and coal because of its fast growth and

\footnotetext{
${ }^{1}$ Universidade de Brasília (UnB), Departamento de Engenharia Florestal (EFL), Brasília, DF, Brazil.

${ }^{2}$ Universidade Federal Rural do Semi-Árido (UFERSA), Centro de Ciências Agrárias (CCA), Departamento de Ciências Agronômicas e Florestais (DCAF), Mossoró, RN, Brasil.

${ }^{3}$ Universidade Federal de Mato Grosso (UFMT), Programa de Pós-Graduação em Ciências Florestais e Ambientais (PPGCFA), Sinop, MT, Brazil.

"Corresponding author: miguelederpereira@gmail.com
}

Received: 10.04.2017 Accepted: 10.04.2018 
considerably favorable energetic characteristics. Some elementary features of wood are directly related to their properties. Among these are the wood density and its response to the propagation of acoustic waves by non-destructive methods. These characteristics are obtained easily and quickly and can be used to estimate the remaining properties of wood. However, these characteristics are still unknown and need to be studied, demanding suitable techniques that could expedite fast and efficient prediction of such characteristics. Considering this, Artificial Neural Networks (ANNs) could be a promising tool.

Artificial Neural Networks (ANNs) are mathematical models that use artificial intelligence in order to solve certain complex problems. These are formed by simple processing elements which are artificial neurons, and are activated by a function called activation function. Neurons are linked together by connections usually associated with coefficients or weights that are adjusted by training algorithms. Neurons are responsible for removing the peculiarities of the database and storing the knowledge of networks.

As basic characteristics, networks have adaptive learning, self-organizing capacity and a robust structure with parallel distribution (layers). They are efficient in learning and generalization, and in addition to being tolerant to outliers, they are also able to model different variables and their non-linear relationships, as well as enabling quantitative and qualitative variable modeling (Kuvendziev et al. 2014, Haykin 2001).

These premises make ANNs stand out, as their adjustment methodology is based on machine learning regardless of the model (Alves et al. 2017), with wide application in agricultural sciences, engineering and medicine. In practice, they are data modeling tools that are widely used in predictions, mappings and pattern recognition, being able to go beyond human capacity to search large databases and relate them to a specific desirable characteristic at the same time (Goyal 2013).

The applicability of artificial neural networks in wood science has already been evaluated by several authors (Tiryaki and Hamzacebi 2014, Tiryaki and Aydin 2014, Okan et al. 2015, Melo and Miguel 2016, Tiryaki et al. 2016, Bardak et al. 2016), which denotes its potentiality. The purpose of this research was to evaluate the potential of ANNs in estimating wood resistance in young individuals of Eucalyptus urograndis, one of the main species used by Brazilian silviculture.

\section{MATERIALS AND METHODS}

\section{Description of the study area and the choice of individuals}

The wood samples were taken from a Eucalyptus urograndis plantation in the city Sinop, Mato Grosso. They were extracted from a clone selected from a 5-year-old Eucalyptus clonal testing plantation. The test was done in a completely arbitrary design with 4 replicates, using a spacing of $3 \times 2 \mathrm{~m}$. To distinguish the clone, ten trees were felled and sampling was performed following the recommendations of the Pan American Standards Commission (COPANT 458, 1972). Prior to the tests, the samples were evaluated through non-destructive testing methods of apparent density, while the dynamic modulus of elasticity was obtained by ultrasound. The hardness, resistance and compressive strength were determined parallel to the fibers. The tests were implemented following the recommendations of the NBR 7190 (Brazilian National Standards Organization - ABNT, 2011).

\section{Determining the Dynamic Modulus of Elasticity $\left(E_{d}\right)$}

The test was conducted in the Pundit Lab of Proceq, which uses a $24 \mathrm{kHz}$ frequency flat transducer and receiver placed in the longitudinal direction of the samples, and when using a coupling (which in this case was solid Vaseline), ultrasonic waves passed through the wood. The calibration of the instrument was done with a calibration block $(25,4 \mu \mathrm{s})$ and automatic precision adjustment. The time and wave propagation velocity were documented for calculating the dynamic modulus of elasticity $\left(E_{d}\right)$ 
of the material. The dynamic modulus of elasticity was calculated by Equation 1.

$$
E d=\frac{V^{2} \rho_{a p}}{9,804 \times 10^{-5}}
$$

In which: $E_{d}=$ dynamic modulus of elasticity $(\mathrm{MPa}) ; \mathrm{V}=$ wave propagation speed $(\mathrm{m} / \mathrm{s}) ; \rho_{\mathrm{ap}}=$ apparent density $\left(\mathrm{kg} / \mathrm{m}^{3}\right)$

\section{Adjustments of ANNs}

For the adjustment of the ANNs, $75 \%$ of the information that composed the database of the (30) samples was randomly selected. The input layer was composed of three neurons, one for each independent variable: wood density $(\rho b)$, velocity $\left(V_{0}\right)$ and dynamic modulus of elasticity $\left(E_{d}\right)$. The output layer was also composed of three neurons, which are (in practice) the response/predictor variables: hardness $\left(f_{H}\right)$, modulus of elasticity $\left(E_{c 0}\right)$ and modulus of rupture $\left(f_{c 0}\right)$, with 1000 networks having been trained.

The ANN adjustment was performed with the help of the Intelligent Problem Solver (IPS) tool of Statistica 7 software (Statsoft 2007), which standardizes the data between 0-1 and tests several architectures, asserting those that best fit the problem. Only MLP (Multilayer Perceptron) networks were selected for the training. According to Silva et al. (2010), this category of networks allows for the neural layer of output to be composed of different neurons, where each corresponds to one of the process outputs to be mapped.

The networks were also made up of a single hidden layer. According to Esquerre (2002), most of the time networks require a single hidden layer to non-linearly solve separable problems. The number of neurons in the hidden layer was also optimized with the Intelligent Problem Solver.

An artificial neuron is the information processing unit of an ANN, formed by " $n$ " inputs $x_{1}, x_{2}, .$. $\mathrm{x}_{\mathrm{n}}$ (dendrites) and an output " $\mathrm{y}$ " (axon). The inputs are associated with weights $\mathrm{w}_{1}, \mathrm{w}_{2}, \ldots, \mathrm{w}_{\mathrm{n}}$ which represent the synapses. These can be negative or positive. Currently, a basic model of an artificial neuron can be represented mathematically as Equation 2:

$$
Y_{k}=\varphi\left(V_{k}\right)
$$

In which: $\mathrm{Y}_{\mathrm{k}}=$ output of the artificial neuron; $\varphi=$ activation function; $\mathrm{V}_{\mathrm{k}}=$ linear combiner result, which is Equation 3:

$$
V_{k}=\sum_{o}^{m} x_{n} w_{n}
$$

The sigmoid function was preferred in activating the ANN training, as it is the most usual in the elaboration of artificial neural networks, and which can approximate any continuous function with precision in well-designed architectures. Mathematically, it is given by Equation 4:

$$
\varphi(v)=\frac{1}{1+\exp ^{\beta u}}
$$


In which: $\boldsymbol{\varphi}=$ sigmoid activation function; $\beta=$ estimation of the parameter that determines curve of the sigmoid function; $\mathrm{u}=$ potential of the activation function.

Resilient propagation was used as the algorithm for this type of activation function and network category, and the training parameters were a learning rate $(\mu)$ of 0,2 and a momentum term $(\eta)$ of 0,9 .

\section{Network training}

First, the weights of all the networks were randomly generated (Heaton 2011). Next, the individual update value evolved during the learning process based on the error function. A supervised method was adopted for the network training, in which the input and output variables were indicated for the networks. This is a feedforward method and it uses the algorithm for unidirectional data flow without cycles (Haykin 2001). Network training continued until the error rate was reduced to an acceptable range between the predicted values and the actual values supplied to the network, known as the delta rule, or until the maximum number of times or cycles was reached (Shiblee et al. 2010).

The criterion for stopping the training algorithm was reaching the root-mean-square error (RMSE) of less than 1\%, or when the root-mean-square error increased again (as suggested by Chen et al. 2014), so the training was finalized when one of the criteria was reached.

\section{Network Selection and Validation}

The best ANN was selected based on the correlation between observed variables and those estimated by the networks, the stability of the training levels of the networks provided by the software during the training, selection and evaluation phases, which means they must have little variation between them (Miguel et al. 2016), the root-mean-square error in percentage form and a graphical analysis of the residues.

The RMSE evaluates the mean squared error between the observed and the estimated values. The lower the RMSE, the better the average precision of the estimates, with the optimal situation being when it is equal to zero (Mehtätalo et al. 2006) (Equation 5).

$$
\operatorname{RMSE}(\%)=\frac{100}{\bar{x}} \sqrt{\frac{\sum_{1=1}^{n}(x i-\hat{x})^{2}}{n}}
$$

In which: $\bar{x}$ is the average of the variables of interest (hardness, modulus of elasticity and modulus of rupture); are the variables predicted by ANN; $x i$ are the individual values of each variable, and " $n$ " are the total number of observations related to each variable.

An independent sample corresponding to $25 \%$ of the database samples (10 of them) was randomly selected in order to validate the results. The chosen criteria to validate the adjustments were the Chisquared test $\left(\chi^{2}\right)$, an aggregated difference in percentage $(\mathrm{AD} \%)$ and the graph of the behavior between observed and estimated values.

\section{RESULTS AND DISCUSSION}

\section{Parameters employed evaluating the networks}

The mean values of density, wave propagation velocity, dynamic modulus of elasticity, hardness, modulus of elasticity and rupture of parallel compression are shown in Table 1 . The values observed in 
density were similar to those observed by Bassa et al. (2007) in studying hybrids from the same species at age 7, and found density values of 521 and $543 \mathrm{~kg} / \mathrm{m}^{3}$, respectively.

The values of elasticity $\left(E_{c 0}\right)$ and resistance $\left(f_{c 0}\right)$ obtained by the compression test parallel to the fibers can also be observed in Table 1. The mean value of elasticity found in Eucalyptus urograndis was $14721 \mathrm{MPa}$. Studying Eucalyptus grandis wood at the age of 15 years, Stangerlin et al. (2008) found mean values of elasticity for the compression test parallel to the fibers of $13119 \mathrm{MPa}$ near the marrow, and $16944 \mathrm{MPa}$ near the trunk bark.

Table 1. Descriptive statistics of the analyzed variables.

\begin{tabular}{|l|l|l|l|l|l|l|}
\hline & \multicolumn{1}{|c|}{$\begin{array}{c}\text { Density } \\
\left(\mathrm{kg} / \mathrm{m}^{3}\right)\end{array}$} & \multicolumn{1}{|c|}{$\begin{array}{c}\text { Velocity } \\
(\mathrm{m} / \mathrm{s})\end{array}$} & $\begin{array}{c}\mathrm{Ed} \\
(\mathrm{MPa})\end{array}$ & $\begin{array}{c}\mathrm{f}_{\mathrm{H}} \\
(\mathrm{N})\end{array}$ & $\begin{array}{c}\mathrm{E}_{\mathrm{c} 0} \\
(\mathrm{MPa})\end{array}$ & $\begin{array}{c}\mathrm{f}_{\mathrm{c} 0} \\
(\mathrm{MPa})\end{array}$ \\
\hline Minimum & 500 & 4831 & 12516 & 1851 & 8526 & 35,5 \\
\hline Mean & 540 & 5148 & 14721 & 2563 & 10549 & 42,9 \\
\hline Maximum & 640 & 5420 & 18030 & 3822 & 13373 & 52,9 \\
\hline $\begin{array}{l}\text { Standard } \\
\text { Deviation }\end{array}$ & 2 & 172,43 & 1353,34 & 453,38 & 897 & 3,17 \\
\hline CV (\%) & 5,04 & 3,35 & 9,19 & 17,69 & 8,51 & 7,41 \\
\hline
\end{tabular}

\section{Network elaboration}

Consequently, the best ANN was selected from the 30 samples used to train the networks,. It was composed of an input layer that was constituted by three (3) neurons: density $(\rho)$, wave propagation velocity (Vo) and dynamic modulus of elasticity $\left(E_{d}\right)$.

The hidden layer was composed of a single layer, as previously defined (Esquerre 2002, Melo and Miguel 2016). According to Cybenko (1989), this single layer is supported by the universal approximation theorem, which is sufficient for an MLP-like network to approach any continuous function. Also, its number of neurons as determined by the Intelligent Problem Solver (IPS) tool was seven (7) neurons. Finally, an output layer constituted by three (3) neurons: hardness $\left(f_{H}\right)$, modulus of elasticity $\left(E_{c 0}\right)$ and modulus of rupture $\left(f_{c 0}\right)$, as shown in Figure 1.

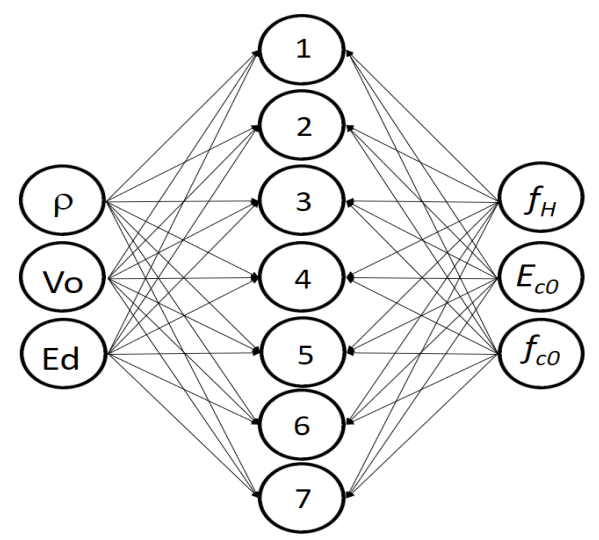

Figure 1. Graphic scheme of the selected network. 


\section{Network training}

The statistics for precision adjustment of the selected networks in predicting hardness, modulus of elasticity and modulus of tree rupture of Eucalyptus sp. were efficient. The selected ANN presented low variation between the levels of training, selection and evaluation, and ideal results in exhibiting training stability (Binoti et al. 2013). The correlation between observed and estimated hardness, modulus of elasticity and modulus of rupture was of 0,$95 ; 0,96$ and 0,97 with the root-mean-square error in percentage form (RMSE\%) of 7,52\%; 3,43\% and 2,56\% respectively (Table 2 ).

Thus, the use of neural networks effectively sums the estimates of wood properties, and at the same time dispenses the basic assumptions of conventional mathematical modeling such as normality and linearity between predicted and predictor variables (Egrioglu et al. 2014). These attributes often have to undergo different mathematical transformations to be modeled in a traditional way, and can lead to losses in quality and selection of models (Miguel et al. 2016). In addition to these characteristics, ANNs present certain advantages under conventional techniques, highlighting its generalization capacity, parallelism and the possibility of learning, which result in accurate values according to the outcome of the research.

Table 2. Characteristics and performance statistics of artificial neural networks selected to estimate the hardness, modulus of elasticity and modulus of rupture in Eucalyptus sp. wood in Brazil.

\begin{tabular}{|c|c|c|c|c|c|c|c|c|c|c|}
\hline \multirow{2}{*}{ Network } & \multirow{2}{*}{$\begin{array}{l}\text { Predictor } \\
\text { variables }\end{array}$} & \multirow{2}{*}{$\begin{array}{l}\text { Predicted } \\
\text { variables }\end{array}$} & \multicolumn{3}{|c|}{ Neurons by layer } & \multicolumn{5}{|c|}{ Adjustment } \\
\hline & & & Input & Hidden & Output & LT & LS & LA & $y \hat{x}$ & RMSE\% \\
\hline ANN & $\begin{array}{c}\text { Density } \\
\text { Velocity } \\
E_{d}\end{array}$ & $\begin{array}{l}f_{H} \\
E_{c 0} \\
f_{c 0}\end{array}$ & 3 & 8 & 3 & 0,10 & 0,12 & 0,11 & $\begin{array}{l}0,95 \\
0,96 \\
0,97\end{array}$ & $\begin{array}{l}7,52 \\
3,45 \\
2,56\end{array}$ \\
\hline
\end{tabular}

$E_{d}=$ dynamic modulus of elasticity, $f_{H}=$ hardness, $E_{c 0}=$ modulus of elasticity, $f_{c 0}=$ modulus of rupture, $\mathrm{LT}=$ levels of training (network acquisition), $\mathrm{LS}=$ levels of stop selection (training stop), LA = levels of assessment (trained network quality), $y x x=$ correlation between observed and estimated variables, RMSE $\%=$ root-mean-square error in percentage.

Even if the statistical goodness-of-fit criteria presented are suitable indicators for the selection of a neural network, the graphic analysis of residues is fundamental to corroborate them (Draper and Smith 1981), since this type of analysis detects possible underestimation trends in predicting the variables of interest, which are not measured by the statistics that evaluate precision.

The graphs of the correlation between observed and estimated variables by the ANN of the properties $f_{H}, E_{c 0}$ and $f_{c 0}$ with the actual values (A1, B1 and $\left.\mathrm{C} 1\right)$, with residue distribution as a percentage (A2, B2 and $\mathrm{C} 2$ ) and error frequency histogram of the trained network (A3, B3 and C3) are shown in Figure 2. It is possible to observe that the selected ANN presents adequate estimated behavior, with flexibility to adhere to the data. The residual graph shows an absence of network trends such as maximum errors of $\pm 30 \%$ for all predicted properties. The evaluation of residues in the form of histograms is an indicated analysis to complement the dispersion graphs and thus avoid misinterpretations, since several points overlap the residual graph. Regarding this, the trained network presented a frequency of adequate errors, with the great majority in the classes varying between $-10 \%$ and $10 \%$ error.

The statistics presented in Table 2 indicate accuracy, as they are in accordance with the residual distribution and histograms of errors (Figure 2). Like this, the ANN was able to accurately predict the characteristics $f_{H}, E_{c 0}$ and $f_{c 0}$ from Eucalyptus $s p$. wood from the interface of wood density attributes, wave propagation velocity and dynamic modulus of elasticity. 

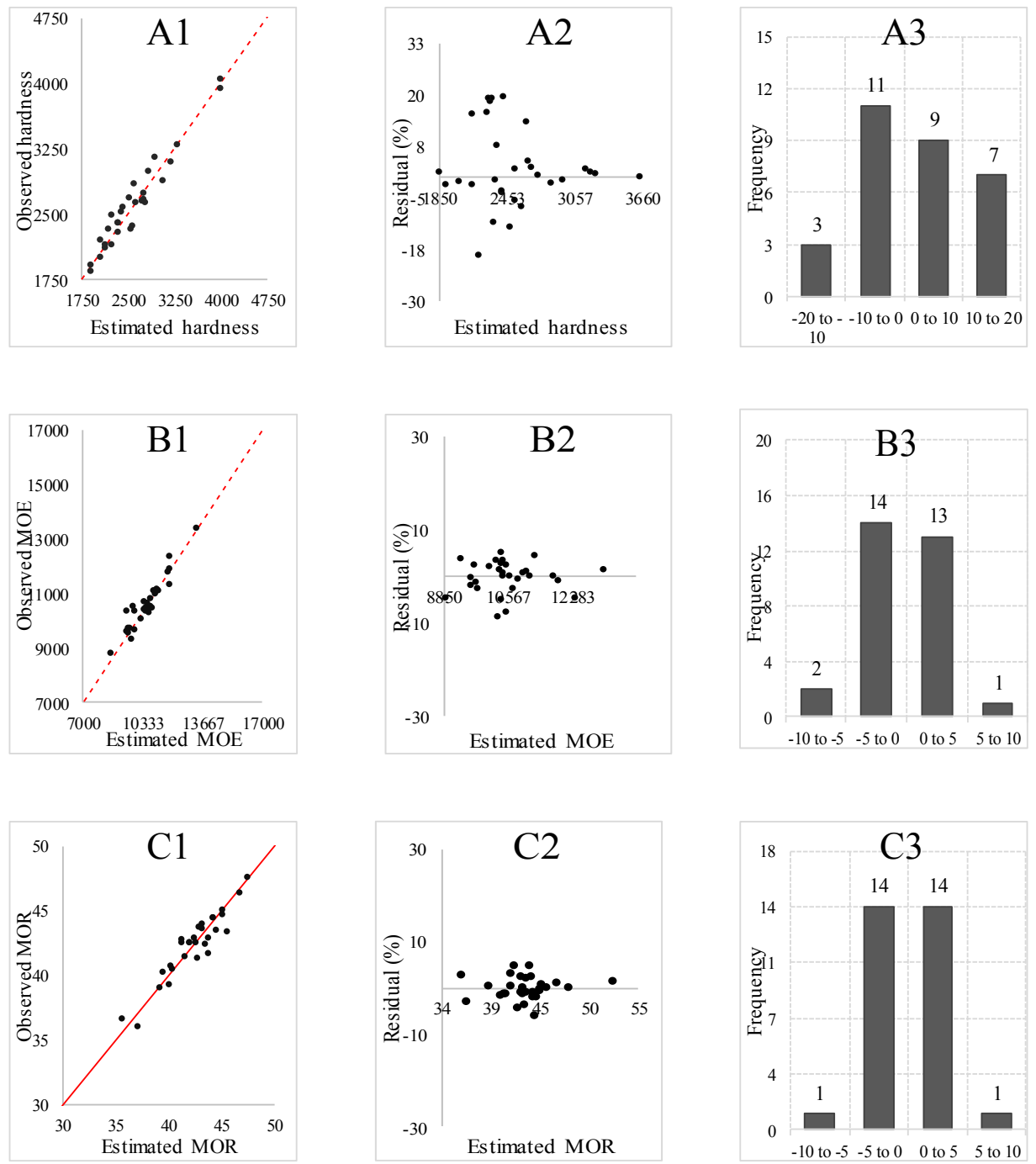

Figure 2. Adjustment correlation of selected ANN in the prediction of hardness, $E_{c 0}$ and $f_{c 0}(\mathrm{~A} 1$, B1 and $\mathrm{C} 1$ ), residual distribution (A2, B2 and $\mathrm{C} 2$ ) and frequency of error histogram (A3, B3 and C3) for Eucalyptus sp. agglomerated panels, Brazil.

\section{Neural network validation}

The validation of the trained network statistically confirmed the viability of the use of artificial intelligence (AI) tools in the prediction of Eucalyptus sp. wood properties (Table 3). During the validation process, 10 samples $(25 \%)$ of the experimental data (not used for the network training) were used, thus proving that samples should be independent of the adjustment base (Zucchini 2000). Next, the data predicted by the ANN was compared with the observed values and later subjected to the Chisquared test to be validated and to the aggregated difference test in percentage and the mean prediction error (Table 3). 
In evaluating the estimates of the properties $f_{H}, E_{c 0}$ and $f_{c 0}$, the values predicted by the network were close to the real values from the mechanical analysis; a concurrence later verified by the Chi-squared test $\left(\chi^{2}\right)$. Thus, the use of artificial neural networks proved to be a reliable technique in estimating these mechanical properties using density, wave propagation velocity and dynamic modulus of elasticity as predictive attributes (Table 3 ).

The aggregated difference, or the sum of the observed and estimated values, serves as the indicator criterion of under or overestimations. The trained network presented the following positive values: $1,92 \% ; 0,45 \%$ and $0,26 \%$, indicating a slight underestimation in predicting the properties $f_{H}, E_{c 0}$ and $f_{c 0}$ of the agglomerated panels (Table 3 ). These low values along with the non-significant result of the Chi-squared analysis demonstrate the effectiveness of the neural networks in predicting the panels' mechanical properties.

Table 3. Mean, minimum and maximum values observed and estimated by ANN in the prediction of hardness $\left(f_{H}\right)$, modulus of elasticity $\left(E_{c 0}\right)$ and modulus of rupture $\left(f_{c 0}\right)$ of the Eucalyptus sp., Brazil.

\begin{tabular}{|c|c|c|c|c|c|c|c|}
\hline Variables/properties & Minimum & Mean & Maximum & $\mathrm{AD}(\%)$ & $\left(\chi^{2}\right)_{\text {D.cal }}$ & $\left(\chi^{2}\right)_{\text {D.ref }}$ & Result \\
\hline observed $f_{H}$ & 2147 & 2265 & 3823 & \multirow{2}{*}{1,92} & \multirow{2}{*}{14,55} & \multirow{6}{*}{16,92} & \multirow{2}{*}{ ns } \\
\hline estimated $f_{H}$ & 2217 & 2620 & 3697 & & & & \\
\hline observed $E_{c 0}$ & 9852 & 10596 & 12063 & \multirow{2}{*}{0,45} & \multirow{2}{*}{12,21} & & \multirow{2}{*}{ ns } \\
\hline estimated $E_{c 0}$ & 9765 & 10567 & 11899 & & & & \\
\hline observed $f_{c 0}$ & 35,49 & 42,73 & 47,99 & \multirow{2}{*}{0,26} & \multirow{2}{*}{3,68} & & \multirow{2}{*}{ ns } \\
\hline estimated $f_{c 0}$ & 36,50 & 42,41 & 47,05 & & & & \\
\hline
\end{tabular}

Neural networks currently represent a promising area for multidisciplinary research (Silva et al. 2010), and the use of ANN in Brazil has become important in estimating measurements of forest stands, as it is considered an efficient and promising technique by several researchers (Leite et al. 2011, Castro et al. 2013, Binoti et al. 2015, Miguel et al. 2015). Nevertheless, studies are scarce when describing the physical and mechanical properties of wood and its engineered products to predict the quality of agglomerated panels (Melo and Miguel 2016).

For the validation process, predictive learning ability, compact and homogeneous residuals, and distribution of errors in class intervals close to zero are desirable regardless of the modeling technique, since they demonstrate the ability of the models to estimate the variables of interest with precision. Similar to the training, ANN was effective in predicting $f_{H}, E_{c 0}$ and $f_{c 0}$ properties of wood, presenting residue adhesion, compactness, and homogeneity. It is also remarkable how the histogram of errors presented the highest frequency close to zero (Figure 3). Finally, the network maintained errors of overestimation and underestimation at less than $30 \%$, once again following the same behavior presented in the training phase.

The results found in this research concur with the statements of Egrioglu et al. (2014), when mentioning that ANNs have advantages over conventional techniques due to their generalization capacity, parallelism and possibility of learning. As such, they can extract standards from a certain database (learning) and adequately reapply them in others. Hence, their use is highly recommended.

The Chi-squared test evidenced adherence and the aggregated difference (AD) revealed a high accuracy of the selected ANN for simultaneous outputs (three neurons in the output layer) in the prediction of mechanical properties of $f_{H}, E_{c 0}$ and $f_{c 0}$. Thus, this research is of great value because it positively impacts the prediction of these products' quality through the exclusive use of non-destructive chemical and mechanical variables (density, velocity and dynamic modulus of elasticity) as predictor 
variables.
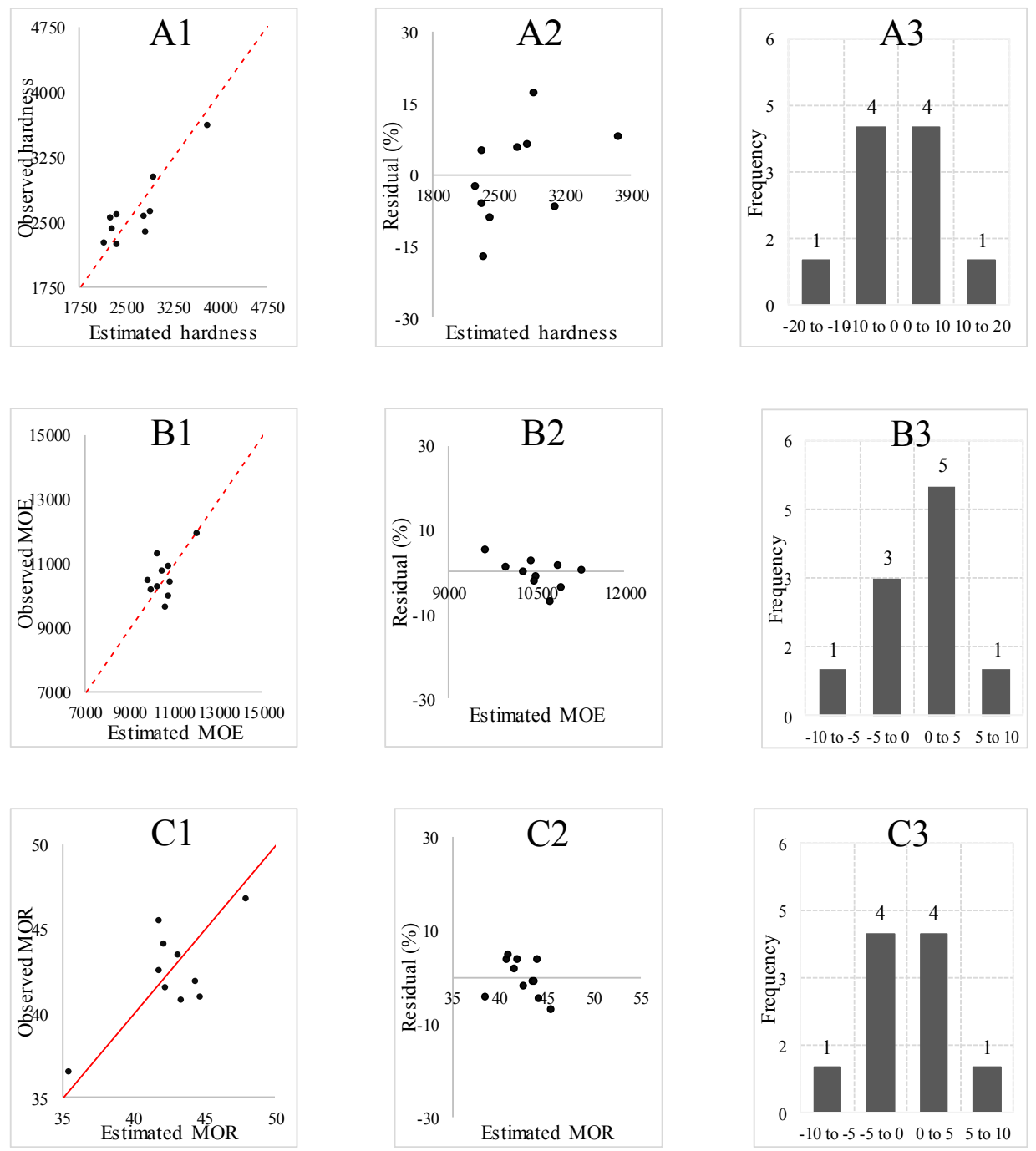

Figure 3. ANN validation in the correlation information of the adjustment in the prediction of $f_{H}, E_{c 0}$ and $f_{c 0}(\mathrm{~A} 1, \mathrm{~B} 1$ and $\mathrm{C} 1)$, residual distribution (A2, B2 and $\left.\mathrm{C} 2\right)$ and frequency error histogram (A3, B3 and C3) for Eucalyptus sp. agglomerated panels, Brazil.

Considering this research, it is worth emphasizing that the results obtained and presented are specific for the evaluated species (Eucalyptus urograndis). Further studies should be carried out to study other species as well as different ages, and consequently different configurations and architectures of neural networks should be trained. As a suggestion, the insertion of "species" and "age" as categorical variables in the input layer is an interesting alternative, as it may result in a single ANN capable of accurately predicting mechanical characteristics of wood for a range of species at different ages. 


\section{CONCLUSIONS}

Simultaneously-adjusted multilayered perceptron artificial neural networks (three neurons in the output layer) which use information of density, wave propagation velocity and dynamic modulus of elasticity as predictor variables are accurate in estimating mechanical properties of hardness, modulus of elasticity and modulus of rupture of the Eucalyptus urograndis wood, and do not statistically differ from the values obtained through destructive mechanical test.

Therefore, Multilayer Perceptron ANNs are a practical and efficient tool in mechanical-technological wood testing. The results indicate that this tool can be used in a practical way by industries of the timber sector to effectively and non-destructively predict the performance of wood parts.

\section{REFERENCES}

Alves, D. P.; Tomaz, R. S.; Laurindo, B. S.; Laurindo, R. D. F.; Silva, F. F.; Cruz, C. D.; Nick, C.; Silva, D. J.H. 2017. Artificial neural network for prediction of the area under the disease progress curve of tomato late blight. Scientia Agricola 74(01): 51-59.

Associação Brasileira de Normas Técnicas. ABNT. 2001. Projetos de estruturas de madeira. NBR 7190. Rio de Janeiro.

Bassa, A. G. M. C.; Silva Júnior, F. G.; Sacon, V. M. 2007. Misturas de madeira de Eucalyptus gradis x Eucalyptus urophylla e Pinus taeda para produção de celulose kraft através do Processo LoSolids. Scientia Forestalis 75(4): 19-30.

Bardak S.; Tiryaki S.; Nemli, G.; Aydın A. 2016. Investigation and neural network prediction of wood bonding quality based on pressing conditions. International Journal of Adhesion and Adhesives 68(5): 115-123.

Binoti M. L. M. S.; Binoti, D. H. B.; Leite, H. G. 2013. Aplicação de redes neurais artificiais para estimação da altura de povoamentos equiâneos de eucalipto. Revista Árvore 37(4): 639-645.

Binoti, M. L. M. S.; Leite, H. G.; Binoti, D. H. B.; Gleriani, J. M. 2015. Prognose em nível de povoamento de clones de eucalipto empregando redes neurais artificiais. Cerne 21(1): 97-105.

Castro, R. V. O.; Soares, C. P. B.; Leite, H. G.; Souza, A. L.; Nogueira, G. S.; Martins, F. B. 2013. Indiv'idual growth model for Eucalyptus Stands in Brazil using artificial neural network. ISRN Forestry: Article ID 196832.

Chen, W. C.; Tseng, L.Y.; Wu, C. S. 2014. A unified evolutionary training scheme for single and ensemble of feedforward neural network. Neurocomputing 143(C): 347-361. 458.

Comisión Panamericana de Normas Técnicas. COPANT. 1972. Seleção das amostras. COPANT

Cybenko, G.V. 1989. Approximation by superpositions of a sigmoidal function. Mathematics of Control, Signals and System 2(4): 303-314.

Draper, N. R.; Smith, H. 1981. Applied regression analysis. New York: Jonh Willey \& Sons 407 p.

Egrioglu, E.; Yolcu, U.; Aladag, C.H.; Bas, E. 2014. Recurrent multiplicative neuron model artificial neural network for non-linear time series forecasting. Procedia - Social and Behavioral 
Sciences 109(8): 1094-1100.

Esquerre, K.P.O.; Mori, M.; Bruns, R.E. 2002. Simulation of an industrial wastewater treatment plant using artificial neural networks and principal components analysis. Brazilian Journal of Chemical Engineering 19(4): 365-370.

Goyal, S. 2013. Artificial neural networks in vegetables: a comprehensive review. Scientific Journal of Crop Science 2(7): 75-94.

Haykin, S. 2001. Redes neurais: princípios e prática. Porto Alegre: Bookman, 900p.

Heaton, J. 2011. Programming Neural Networks with Encog3 in Java. 2ed. St. Louis: Heaton Research Incorporated, 240p.

Leite, H. G.; Silva, M. L. M.; Binoti, D. H. B.; Fardin, L.; Takizawa, F. H. 2011. Estimation of inside-bark diameter and heartwood diameter for Tectona grandis Linn. trees using artificial neural networks. European Journal of Forest Research 130(2): 263-269.

Kuvendziev A. S.; Lisichkova K.; Zekovic, Z.; Marinkovski, M. 2014. Artificial neural network modelling of supercritical fluid $\mathrm{CO}_{2}$ extraction of polyunsaturated fatty acids from common carp (Cyprinus carpio L.) viscera. J Supercrit Fluids 92(6):242-248.

Mehtätalo, L.; Maltamo, M.; Kangas, A. 2006. The use of quantile trees in the prediction of the diameter distribution of a stand. Silva Fennica 40(3):501-516.

Miguel, E. P.; Rezende, A. V.; Leal, F. A.; Matricardi, E. A.; Vale, A. T.; Pereira, R. S. 2015. Redes neurais artificiais para a modelagem do volume de madeira e biomassa do cerradão com dados de satélite. Pesquisa Agropecuária Brasileira 50(9): 829-839.

Miguel, E.P.; Mota, F. C. M.; Teo, S. J.; Nascimento, R. G. M.; Leal, F.A.; Pereira, R. S.; Rezende, A.V. 2016. Artificial intelligence tools in predicting the volume of trees within a forest stand. African Journal of Agricultural Research 11(21): 1914-1923.

Melo, R.R.; Miguel, E.P. 2016. Use of artificial neural networks in predicting particleboard quality parameters. Revista Arvore 40(5): 949-958.

Okan, O.T.; Deniz, I.; Tiryaki, S. 2015. Application of artificial neural networks for predicting tensile index and brightness in bleaching pulp. Maderas-Cienc Tecnol 17(3): 571-584.

Shiblee, M.D.; Chandra, B.; Kalra, P.K. 2010. Learning of geometric mean neuron model using resilient propagation algorithm. Expert Systems with Applications 37(12): 7449-7455.

Silva, I.N.; Spatti, D.H.; Flauzino, R.A. 2010. Redes Neurais Artificiais para engenharia e ciências aplicadas. São Paulo: Artliber. 397p.

Stangerlin, D. M.; Calegari, L.; Santini, E. J.; Domingues, J. M. X.; Gatto, D. A.; Melo, R. R. 2008. Determinação do módulo de elasticidade em madeiras por meio de métodos destrutivo e não destrutivo. Revista Brasileira de Ciências Agrárias 3(2): 145-150.

Tiryaki, S.; Aydın, A. 2014. An artificial neural network model for predicting compression strength of heat treated woods and comparison with a multiple linear regression model. Construction and Building Materials 62(13): 102-108.

Tiryaki, S.; Hamzacebi, C. 2014. Predicting modulus of rupture (MOR) and modulus of elasticity (MOE) of heat treated woods by artificial neural networks. Measurement 49(3): 266-274.

Tiryaki, S.; Bardak, S.; Aydın, A.; Nemli, G. 2016. Analysıs of volumetrıc swellıng and shrınkage of heat treated woods: experımental and artıficial neural network modelıng approach. Maderas-Cienc Tecnol 18(3): 477-492. 
Zucchini, W. 2000. An introduction to model selection. Journal of Mathematical Psychology 44(1): 41-61. 